\title{
Diagnostic Accuracy of Magnetic Resonance Imaging in Infective Vertebral Lesions
}

\author{
Showkat $\mathrm{S}^{1}$, Ghafoor $\mathrm{N}^{2}$, Bhowmik B ${ }^{1}$, Nabi $\mathrm{S}^{3}$, Jahan $\mathrm{MU}^{4}$, Nuruzzaman $\mathrm{SM}^{5}$ \\ ${ }^{I}$ Department of Radiology and Imaging, Bangabandhu Sheikh Mujib Medical University, Dhaka, \\ Bangladesh; ${ }^{2}$ Department of Radiology and Imaging, Ibrahim Cardiac Hospital and Research \\ Institute, Dhaka, Bangladesh; ${ }^{3}$ Department of Radiology and Imaging, Dhaka Medical College, \\ Dhaka, Bangladesh; ${ }^{4}$ Bangladesh Medical Research Council, Dhaka, Bangladesh; ${ }^{5}$ Department of \\ Radiology and Imaging, Green Life Medical College, Dhaka, Bangladesh
}

\begin{abstract}
Background: Infective vertebral lesions usually involve the vertebral column, including the bone, intervertebral disk and paravertebral soft tissues. Variable imaging characteristics in conjunction with clinical findings can facilitate early diagnosis and treatment. MRI is a powerful imaging tool that can be help to evaluate spinal pathology specially infection. Typical MRI findings of infective vertebral disease are vertebral endplate destruction, bone marrow and intervertebral disc signal intensity changes and para vertebral soft tissue involvement.
\end{abstract}

Objective: This study was aimed to assess whether the MRI can different the in differentiate the invective vertebral lesions from benign or malignant Tumors.

Methods: This cross-sectional study was conducted on a total of 52 clinically suspected patients of infective vertebral lesions to establish diagnostic accuracy of MRI. The validity of MRI diagnosis for infective vertebral lesion was compared against CT-guided fine needle aspiration cytological (FNAC) diagnosis.

Results: The sensitivity, specificity, positive and negative predictive values (PPVs and NPVs) and finally diagnostic accuracy of MRI were calculated by comparing the MRI diagnoses with those of fine needle aspiration cytological diagnosis of vertebral lesions. Finally the sensitivity, specificity, PPV and NPV of MRI diagnosis for infective vertebral lesion were $95.6 \%, 85.7 \%, 97.7 \%$ and $75.0 \%$ respectively. The overall diagnostic accuracy was $94.2 \%$.

Conclusion: Finding of this study suggested that MRI should be considered as the imaging modality of choice for patients with suspected infective vertebral lesions.

Keywords: MRI, Vertebral infection, Fine needle aspiration cytology, Predictive value

\section{Introduction}

Infective vertebral lesion is defined as an infectious disease affecting the vertebral body, the intervertebral disc and adjacent para spinal tissue. Vertebral column infection may cause significant neurological deficits and structural deformity which may lead to significant morbidity and mortality. Anatomical location of infection is vertebral column, intervertebral disc, the spinal canal and adjacent soft tissue. Pyogenic spondylitis and tuberculous spondylitis are common causes of spinal infection. ${ }^{1}$ A etiologically, spinal infections can be described as pyogenic, granulomatous and parasitic. Most bacteria cause pyogenic infections, whereas mycobacteria, fungi, brucella, and syphilis

*Correspondence: Dr. Nusrat Ghafoor, Department of Radiology and Imaging Ibrahim Cardiac Hospital and Research Institute, Dhaka, Bangladesh. e-mail: ghafoornusrat@yahoo.com; ORCID: 0000-0002-7351-3099 induce granulomatous reactions. $^{2}$ Vertebral osteomyelitis commonly occurs in the lumbar region, followed by thoracic and cervical spine (less than $10.0 \%){ }^{3}$ Spondylitis is most commonly caused by Mycobacterium tuberculosis. ${ }^{4}$ Tuberculous spondylitis has been common in developing countries, but the number of patients with the disease is also increasing recently in developed countries. $^{5}$

Vertebral column can also affect by non-infective lesion which include primary neoplasm and metastasis. Spinal metastases are the most common tumors of the spine, comprising approximately $90 \%$ of masses encountered with spinal imaging. The most common primary malignancies predominantly metastasizing to the spine include the following tumors in descending order: breast $(21.0 \%)$, lung 
$(19.0 \%)$, prostate $(7.5 \%)$, renal $(5.0 \%)$, gastrointestinal $(4.5 \%)$, and thyroid $(2.5 \%){ }^{6}$

Different pathology of the vertebral column may present with differing imaging characteristics Magnetic Resonance Imaging (MRI) due to its multiplanar capabilities, excellent soft tissue contrast and simultaneous visualization of neural elements is the modality of choice for imaging of spinal infection. ${ }^{7}$ MRI is superior to the other imaging modalities in detecting bone marrow lesions, vertebral abnormalities and even faint lytic/sclerotic bone lesions, since it has high sensitivity in detecting small changes in the fat and water components of the medullary bone, intervertebral discs, spinal cord, and soft tissues around the vertebrae. ${ }^{7} \mathrm{MRI}$ is the gold standard imaging modality for spinal infections with complementary roles in select cases for $\mathrm{CT}$ and nuclear medicine imaging, particularly ${ }^{67} \mathrm{Ga} /{ }^{99 m} \mathrm{Tc}$ scintigraphy and FDG-PET. ${ }^{8}$ However, confirmatory diagnosis is done by cytopathology.

MRI is the neuroimaging of choice for spinal tuberculosis. It is more sensitive than X-ray and more specific than CT in the diagnosis of spinal tuberculosis. But the diagnosis must be established by biopsy before starting antitubercular treatment. ${ }^{9}$ Image guided fine needle aspiration cytology (FNAC) has emerged as the first line of investigation in the evaluation of radiologically detected vertebral and paravertebral lesions. FNAC is a safe, less traumatic, rapid and easy method compared to larger core or open biopsy. ${ }^{10}$ Moreover, this procedure is cost-effective as well as easier to repeat, if necessary. FNAC is of particular importance in suspected infection where a chemotherapeutic agent may be indicated and in suspected metastatic disease where it may be helpful in identifying the nature and probable site of the primary tumor. ${ }^{11}$ This study was intended to assess whether MRI can fairly differentiate infective vertebral lesions from benign or malignant tumors of vertebral column so that effective treatment can be given.

\section{Materials and Methods}

This Cross-sectional study was carried out in the Department of Radiology and Imaging, Bangabandhu Sheikh Mujib Medical University (BSMMU), Dhaka, over a period of two years from July 2017 to July 2019. Purposive sampling was done and sample size was determined by power analysis for a single proportion. Therefore, target sample size was 56 . Out of this sample size 4 patients were excluded due to inconclusive material for cytopathological report.
Patient with clinically suspected infective vertebral lesions attending the Department of Radiology \& Imaging, BSMMU, Dhaka, for MRI scan was included in this study. Patient refused to do CT guided fine needle aspiration cytology for major concomitant disease, recent myocardial infarction, recent cerebrovascular disease; uncontrolled diabetes mellitus was excluded from this study. Data was collected by a pre-designed proforma. Patient's information was obtained using information sheet which includes questionnaire, clinical findings, radiological and cytopathological findings.

Patients with clinically suspected infective vertebral lesions underwent MRI examination. MRI scan will be performed on 1.5 Tesla (SIEMENS, Avanto, Germany). MR images were acquired with the following sequences: Sagittal T1 and T2 weighted images by using spin-echo and fast spin-echo technique. Axial images were obtained with T1 weighted spin echo sequence and proton density weighted. Post contrast T1 SAG, T1 TRA and T1 FS AXIAL has taken.

All patients under went MRI scan followed by CTguided fine needle aspiration cytology.

After explaining the procedure to the patient and taking an informed written consent. A CT image was taken. Then the site of the lesion and shortest route was determined for passage of the needle avoiding adjacent neurovascular structures. The type of posterior approach (posterolateral, transpedicular, or transcostovertebral) could be tailored to the specific location of the lesion. Once a safe path to the target lesion has been chosen, the entry site on the skin surface is marked with an indelible ink marker. A 18 or 21 gauze spinal needle with stylet was used. Needle was introduced with outmost precaution. Direction and presence of needle tip within the target site of lesion was ensured with $\mathrm{CT}$ scan monitor display. Specimen retrieval by means of fine-needle aspiration requires an in-and-out motion within the lesion matrix. When sufficient amount of tissue was taken, needle was removed with caution. Material obtained with a find needle is expelled onto appropriately leveled glass slides. Alcohol fixation is done by dipping the slides in $95 \%$ ethyalcohol. Slides were prepared in conventional method. Lastly again a CT cut were taken to exclude any complications. Cytopathological examination was performed and reports were collected and compare with MRI findings.

Statistical analyses of the results were carried out by using window based computer software devised with Statistical Packages for Social Sciences (SPSS-20). For the validity of study outcome, sensitivity, specificity, accuracy, positive predictive 
value and negative predictive value of magnetic resonance imaging in the diagnosis of vertebral lesions were calculated.

Prior to the commencement of this study, the research protocol was approved by the Institutional Review Board of the BSMMU. The aims and objective of the study along with its procedure, alternative diagnostic methods, risk and benefits were explained to the patients in easily understandable local language and then informed consent was taken from each patient. It was assured that all records would be kept confidential and be used for research purpose only.

\section{Results}

Over half (53.8\%) of the patients was 41-60 years old with mean age of the patients being 46 years (range: $16-71$ years). Nearly two-thirds $(65.0 \%)$ of the patients were male with male to female ratio being roughly $2: 1$ (table I).

Table I: Distribution of the study patients by demographic variables $(\mathrm{n}=52)$

\begin{tabular}{lll}
\hline Demographic variables & Frequency & Percentage \\
\hline $\begin{array}{l}\text { Age (years) } \\
\quad<21 \text { year }\end{array}$ & 4 & 7.7 \\
21-40 years & 12 & 23.1 \\
41-60 years & 28 & 53.8 \\
$\quad$ 61-80 years & 8 & 15.4 \\
Sex & & \\
$\quad$ Male & 34 & 65.4 \\
$\quad$ Female & 18 & 34.6 \\
*Mean age $=46.1 \pm 13.1$ yrs; range $=(16-71)$ years.
\end{tabular}

Patients invariably presented with back pain, functional disability and tenderness. The next predominant symptom was muscle spasm (84.5\%), fever $(75.0 \%)$ followed by neurological deficit (51.9\%) and bladder involvement (48.1\%) (figure 1).

Posterior bulge with pathological fracture causing thecal sac indentation was seen in 23 $(44.2 \%)$ and posterior bulge without pathological fracture was seen in 14 (26.9\%) cases. The rest $15(28.8 \%)$ did not exhibit any posterior bulging. Signal change was seen in all cases. Majority $(51.9 \%)$ of the patients had involvement of contiguous vertebra followed by $23.1 \%$ multiple skip lesions, $15.4 \%$ single vertebral involvement and $9.4 \%$ multiple contiguous lesion. Intervertebral disc involvement was seen in $32(61.5 \%)$. Reduction in disc height was $19(36.5 \%)$ cases and discitis was found $13(25 \%)$ cases. Signal change in disc was observed in $13(25.0 \%)$ patients. End-plate irregularity in contiguous vertebral body was seen in $27(51.9 \%)$ patients, end plate irregularity with single vertebral body involvement was detected in $4(7.7 \%)$ patients. Posterior element was involved in 15 (28.8\%) cases. Central involvement was seen in 23 $(44.2 \%)$ cases. Epidural and paravertebral abscess was diagnosed in $27(51.9 \%)$ cases. Soft tissue extension was present in about $60.0 \%$ of the cases and neurological deficit in $28.7 \%$ (table II).

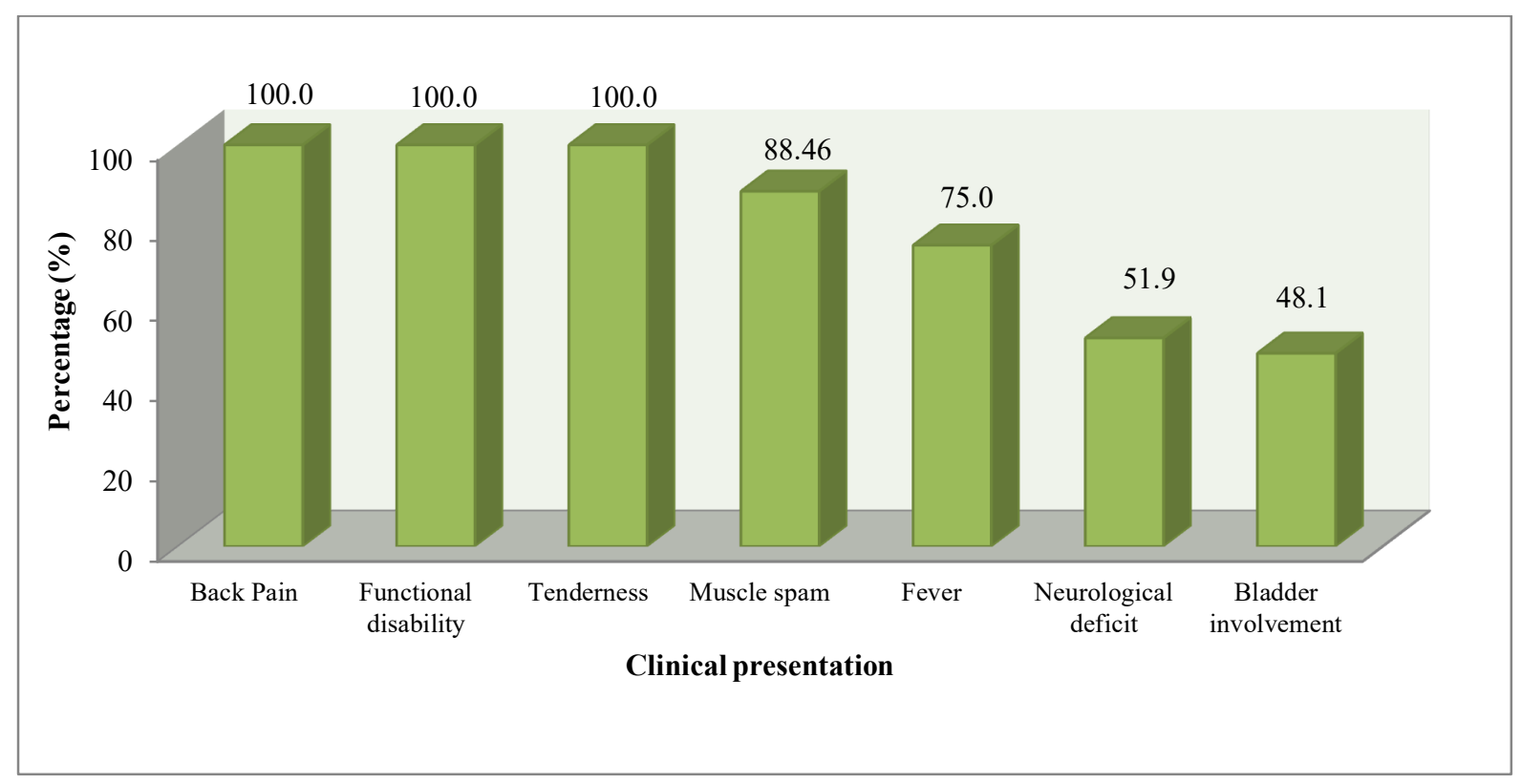

Figure 1: Distribution of patients by clinical presentation $(n=52)$ 

Table II: Number and pattern of vertebral and intervertebral disc involvement: $(\mathrm{n}=52)$

\begin{tabular}{lcc}
\hline $\begin{array}{l}\text { Vertebral and intervertebral } \\
\text { disc involvement }\end{array}$ & Frequency & Percentage \\
\hline $\begin{array}{l}\text { Number of vertebra } \\
\text { involvement }\end{array}$ & & \\
$\quad$ Single & 8 & 15.4 \\
$\quad$ Contiguous & 27 & 51.9 \\
$\quad \begin{array}{l}\text { Multiple skip lesions } \\
\text { Multiple contiguous lesions }\end{array}$ & 12 & 23.1 \\
End plate irregularity & 5 & 9.6 \\
$\quad$ One vertebral body & 4 & \\
$\quad$ Contiguous vertebral body & 27 & 51.9 \\
$\quad$ No irregularity & 21 & 40.4 \\
Intervertebral disc & & \\
$\quad \begin{array}{l}\text { Discitis } \\
\text { Reduction in disc height }\end{array}$ & 13 & 25.0 \\
$\quad$ No involvement & 20 & 36.5 \\
Involvement pattern & & 38.5 \\
Involvement of posterior & & \\
elements/pedicles & 15 & 28.8 \\
Epidural/ Paravertebral \\
abscess
\end{tabular}

*Total will not correspond to $100 \%$ for multiple response

MRI diagnosis shows that 44 (84.6\%) patients had infective, 4 (7.7\%) malignant and another 4 (7.7\%) benign neoplasm. Cytopathological diagnosis revealed that $45(86.6 \%)$ patients were infective, 4 (7.7\%) malignant and $3(5.7 \%)$ benign cases (table III).

Table III: Diagnosis of the cases by screening and confirmatory tests $(\mathrm{n}=52)$

\section{Screening and confirmatory tests \\ Frequency Percentage}

\begin{tabular}{lcc}
\hline MRI diagnosis & & \\
Benign & 4 & 7.7 \\
Malignant & 4 & 7.7 \\
Infective & 44 & 84.6 \\
Cytopathological diagnosis & & \\
Benign & 3 & 5.7 \\
Malignant & 4 & 7.7 \\
Infective & 45 & 86.6 \\
\hline
\end{tabular}

Table IV:Accuracy of MRI in the evaluation of infective vertebral lesion

\begin{tabular}{lccc}
\hline \multirow{2}{*}{$\begin{array}{c}\text { MRI } \\
\text { Diagnosis }\end{array}$} & \multicolumn{2}{c}{ FNAC } & Total \\
\cline { 2 - 3 } & Positive & Negative & \\
\hline Positive & 43 & 1 & $\mathbf{4 4}$ \\
Negative & 2 & 6 & $\mathbf{8}$ \\
Total & $\mathbf{4 5}$ & $\mathbf{7}$ & $\mathbf{5 2}$ \\
\hline
\end{tabular}

The sensitivity of the test is $43 / 45 \times 100=95.6 \%$ and specificity of the test in correctly detecting those who are well-differentiated is $6 / 7 \times 100=$ $85.7 \%$. The positive and negative predictive values of the test are $43 / 44 \times 100=97.7 \%$ and $6 / 8 \times 100=$ $75.0 \%$ respectively, while the percentages of false positive and false negatives are $1 / 44 \times 100=2.27 \%$ and $2 / 8 \times 100=25.0 \%$ respectively. The overall diagnostic accuracy was $(43+6) /(43+2+1+6)=$ 94.2\% (table IV).

\section{Discussion}

In the present study, mean age of the patients was 46 years with lowest and highest ages being 16 and 71 years respectively. A male preponderance was also observed in the series. Khalequzzaman and Hoque in a similar study showed that $43.5 \%$ of their patients were in $3^{\text {rd }}$ decade life (mean age 33.3 years) with a male predominance. ${ }^{12}$ Sivalingam shows male predilection $(63 \%)$ with $\sim 2: 1$ ratio. $^{13}$ More than one-third of the patients in the present study was labor or unemployed indicating that spondylitis is primarily disease of the poor.

Lee et al described that for pyogenic spondylitis, it took on average 6.4 months for the occurrence of clinical signs, which include non-specific pain, fever and neurological manifestation from the compression on spinal cord and nerve root. ${ }^{14}$ For tuberculous spondylitis, it takes 11.2 months on an average. The patients of the present study invariably presented with chronic back pain, functional disability and tenderness. Fever was the next predominant symptom $(75.0 \%)$, followed by neurological deficit $(51.9 \%)$ andbladder involvement (48.1\%). Khalequzzaman and Hoque reported $65.2 \%$ of patients of spondylitis to suffer from low backacheand $91.3 \%$ with functional disability, $41.3 \%$ with fever and $10.8 \%$ with deformity. ${ }^{12}$ In this study, one-third (32.1\%) patients had history of tuberculosis sometimes in the past. While loss of curvature was seen in all cases, thoracic spine involvement was found in $38.5 \%$ and lumbar spine involvement in $30.8 \%$ cases. A few had lesions in thoracolumbar region. Pallewatte \& Wickramasinghe ${ }^{15}$ reported $13.8 \%$ of their patients had a past or present history of 
tuberculosis. Pantaand colleagues noted lumbar spine involvementin $50 \%$ cases, cervical and thoracic spine each in $25 \%$ cases. ${ }^{16}$ Liebegrall et al also described vertebral osteomyelitis to occur more commonly in the lumbar region. ${ }^{17}$

Single vertebra was involved in $15.0 \%$ patients, two vertebra in $52.0 \%$ patients. Posterior element was involved in $29.0 \%$ cases and central involvement was seen in $44.2 \%$ cases. End-plate irregularity in contiguous vertebral body was seen in $52.0 \%$ patients, end plate irregularity with single vertebral body involvement was detected in $7.7 \%$ patients. Panta et al found involvement of multiple vertebrae $(69.2 \%)$ cases and single vertebral involvement in $30.8 \%$ cases. $^{16}$ Only one vertebra involvement is seen early in the course of disease. Only one vertebra endplate involvement is noted most frequently in lumbar spine (26.9\%) followed by cervical spine $(3.8 \%)$.

This study showed posterior bulge with pathological fracture causing thecal sac indentation is seen in $44.2 \%$, posterior bulge without pathological fracture was seen in $26.9 \%$. Signal change in disc was observed in $25.0 \%$ cases, reduction in disc height $36.5 \%$ cases and discitis $25 \%$ cases. Chang et al reported that $57.0 \%$ of a disc was preserved in tuberculous spondylitis, while only $3.0 \%$ was preserved in pyogenic spondylitis. ${ }^{18}$ Ledermann et al observed intervertebral disc involvement was characterized by a loss of disc height producing high signal intensity on $\mathrm{T} 2$ and low signal intensity on $\mathrm{T} 1 .{ }^{19}$

In the present study epidural and paravertebral abscess was found in more than half of the cases which is consistent with the findings of Panta et al epidural collection is most frequently seen at dorsal spine followed by lumbar spine and rarely at cervical spine. ${ }^{16}$ However, significant compression of spinal cord was noted in only two cases in dorsal spine and none in lumbar and cervical spine. All cases of dorsal spine spondylodiscitis demonstrates either prevertebral or paravertebral collection. Perivertebral collection is least common in cervical spine spondylodiscitis.

Epidural extension and epidural abscess formation have been reported to be observed more in tuberculous spondylitis. As paraspinal abscess is formed in tuberculous spondylitis, contrast enhancement is more easily performed in the rim of abscess with the importance of a differential diagnosis. ${ }^{20}$ In other words, paraspinal abscess is frequently found in pyogenic spondylitis; but well- defined paraspinal abnormal signal, thin and smooth abscess wall and presence of paraspinal or intraspinal abscess are more suggestive of tuberculous spondylitis than of pyogenic spondylitis. On the other hand, if the wall of abscess is relatively thick entailing irregular contrast enhancement, it has been reported to be implying pyogenic spondylitis. Loke et al stated that the presence of an air fluid level in paravertebral collections virtually excluded $\mathrm{TB}$, due to the chronicity of the disease. ${ }^{21}$ It did not find any in our case. Soft tissue extension was present in $60.0 \%$ of cases.

Neurological deficit was seen only in 14 (28.7\%) cases. Andronikou et al reported neural deficit in $75 \%$ of his patients. ${ }^{22}$ Hoffman et al showed $60.0 \%$ canal encroachment in a mid-sagittal MR scan with neural deficits. ${ }^{23}$ Subligamentous spread of abscess beneath the anterior longitudinal ligament is observed in most of the cases. This has been reported to be characteristic of TB spine by Liu et al. ${ }^{23}$ Lindahl et al also reported the presence of psoas abscess as characteristic of TB spine. ${ }^{24}$ Here, it was not to be find any case of intradural abscess or intradural extramedullary granuloma; however, an intramedullary granuloma was seen in one patient which resolved following treatment on follow-up MR scan at eight months. Desai reported an extradural granuloma in 6/24 (25\%) cases. $^{25}$ Dhammi et al and Jena et al reported intramedullary granuloma in tubercular spine which resolved on ATT. ${ }^{26,27}$

In the present study MRI diagnosed 44(78.6\%) patients as infective lesion, $4(7.7 \%)$ as malignant and another $4(7.7 \%)$ as benign neoplasm, while FNAC diagnosed $45(86.6 \%)$ patients as infective, $4(7.7 \%)$ as malignant and $3(5.7 \%)$ as benign cases. The sensitivity, specificity, PPV and NPV of MRI diagnosis for infective vertebral lesion were $95.6 \%$, $77.8 \%, 95.6 \%$ and $77.8 \%$ respectively with overall diagnostic accuracy being 92\%. Khalequzzaman and Hoque observed sensitivity and a specificity of MRI in the diagnosis of tuberculous spondylitis to be $95.2 \%$ and $75 \%$ respectively. ${ }^{12}$ Smids et al showed sensitivity of diagnosing spondylodiscitis with MRI to be $67 \%$ and a specificity of $84 \%$, a PPV of $92 \%$, and an NPV of $50 \%$, and an overall diagnostic accuracy of $72 \%{ }^{28}$

\section{Conclusion}

MRI offers excellent visualization of the endplate erosion with changes in bone marrow on both sides of the disk which is a typical finding of infective vertebral 
lesion. Several noninfectious conditions may simulate a spinal infection. Moreover, it has high sensitivity, specificity and diagnostic accuracy in detecting infective vertebral lesion. Thus, MRI can be considered to be the imaging modality of choice for patients with suspected infective vertebral lesions.

\section{Acknowledgement}

Authors are thankful to the study participants their time and cooperation.

Conflict of interest: Authors declared no conflict of interest.

Funding: None

Ethical approval: IRB of BSMMU, Dhaka

Submitted:26 $6^{\text {th }}$ February, 2020

Final revision received: $17^{\text {th }}$ November, 2020

Accepted: $25^{\text {th }}$ November, 2020

Published: $1^{\text {st }}$ December, 2020

\section{Reference}

1. Rothman RH, Simeone FA. The spine. 5th ed. Phila- delphia, PA: Elsevier Saunders, 2006.

2. Herkowitz HN, Garfin SR, Eismont FJ, et al. Roth- man-Simeone the spine. $6^{\text {th }}$ ed. Philadelphia, PA:Elsevier Saunders, 2011.

3. Liebergall M, Chaimsky G, Lowe J, Robin GC, Floman Y. Pyogenic vertebral osteomyelitis with paraly- sis. Prognosis and treatment. Clin OrthopRelat Res. 1991:142-50.

4. Legrand E, Flipo RM, Guggenbuhl P, Masson C, Maillefert JF, Soubrier M, Noël E, Saraux A, Di Fazano CS, Sibilia J, Goupille P, Chevalie X, Cantagrel A, Conrozier T, Ravaud P, Lioté F; Rheumatology Network Organization. Management of nontuberculous infectious discitis. treatments used in 110 patients admitted to 12teaching hospitals in France. Joint Bone Spine. 2001; 68:504-9.

5. Rasouli MR, Mirkoohi M, Vaccaro AR, Yarandi KK, Rahimi-Movaghar V. Spinal Tuberculosis: Diagnosis and Management. Asian Spine J. 2012;6:294-308.

DOI: $10.4184 /$ asj.2012.6.4.294

6. Endrit Z, Vibhu KV, Fassil BM. Cancer, Spinal Metastasis. StatPearls - NCBI, Bookshelf, 2020.

7. Theodore G, Aliyu SH, Brown NM. Spondylodiscitis: Update on Diagnosis and Management. Journal of Antimicrobial Chemotherapy. 2010; 65(SUPPL. 3):11-24.

8. Jason FT, Vinil NS, Alina UDO, Jared N. Rebeca AD, Cynthia TC, David MW. Imaged Based
Approch to Extradural Infections of the Spine. Semin Ultrasound CT MR. 2018; 39:570-586. DOI: $10.1053 /$ j.sult.2018.09.003.

9. Tins BJ, Cassar-Pullicino VN. MR imaging of spinal infection. Semin MusculoskeletRadiol.2004;8:215-229.

10. Gupta RK, Agarwal P, Rastogi H, Kumar S. Phadke RV, Krishnani N. Problems in distinguishing spinal tuberculosis from neoplasia on MRI. Neuroradiology. 1996;38(Suppl 1):S97-104.

11. Saad RS, Clary KM, Lin Y, Silverman JF, Raab SS. Fine needle aspiration biopsy of vertebral lesions. ActaCytol. 2004;48:39- 46.

12. Khalequzzaman S, Hoque HW. Tuberculosis of Spine Magnetic Resonance Imaging (MRI) Evaluation of 42 Cases. Medicine today.2012; 24:59-62.

13. Sivalingam J, Kumar A. Spinal Tuberculosis Resembling Neoplastic Lesions on MRI. J Clin Diagn Res. 2015 Nov;9(11):TC01-3.

DOI: $10.7860 / J C D R / 2015 / 14030.6719$.

14. Lee Y, Kim BJ, Kim SH, Lee SH, Kim WH, Jin SW. Comparative Analysis of Spontaneous Infectious Spondylitis: Pyogenic versus Tuberculous. J Korean Neurosurg Soc. 2018; 61:81-88.

DOI: $10.3340 / \mathrm{jkns} .2016 .1212 .005$.

15. Pallewatte AS, Wickramasinghe NA. Magnetic Resonance Imaging Findings of Patients with Suspected Tuberculosis from a Tertiary Care Centre in Sri Lanka. 2016; 61:185-88.

16. Panta OB, Pathak YR, Karki DB. Magnetic Resonance Imaging Findings in Spondylodiscitis. J Nepal Health Res Counc. 2018 Jan 1;15: 217-221.

17. Liebergall M, Chaimsky G, Lowe J, Robin GC, Floman Y. Pyogenic vertebral osteomyelitis with paralysis. Prognosis and treatment. Clin OrthopRelat Res. 1991:142-150.

18. Chang MC, Wu HTH, Lee $\mathrm{CH}$, Liu CL, Chen TH. Tuberculous spondylitis and pyogenic spondylitis: comparative magnetic resonance imaging features. Spine. 2006;31:782-788.

19. Ledermann HP, Schweitzer ME, Morrison WB, Carrino JA. MR imaging findings in spinal infections: rules or myths? Radiology. 2003;228:506-14.

20. Hoffman EB, Crosier JH, Cremin BJ. Imaging in children with spinal tuberculosis. A comparison of radiography, computed tomography and magnetic resonance imaging. J Bone Joint Surg Br. 1993;75: 233-239. 

21. Loke TK, Ma HT, Chan CS. Magnetic resonance imaging of tuberculous spinal infection. AustralasRadiol. 1997;41:7-12. DOI: 10.1111/j.1440-1673.1997.tb00459.x.

22. Andronikou S, Jadwat S, Douis H. Patterns of disease on MRI in 53 children with tuberculous spondylitis and the role of gadolinium. PediatrRadiol. 2002; 32: 798-805. DOI: $10.1007 / \mathrm{s} 00247-002-0766-8$.

23. Liu GC, Chou MS, Tsai TC, Lin SY, Shen YS. MR evaluation of tubercular spondylitis. Acta Radio. 1993; 34:554-558. DOI: $10.3109 / 02841859309175406$.

24. Lindahl S, Nyman RS, Brismar J, Hugosson C, Lundstedt C. Imaging of tuberculosis. IV. Spinal manifestations in 63 patients. Acta Radiol. 1996;37: 506-511.

DOI: $10.3109 / 02841859609175433$.
25. Desai SS. Early diagnosis of spinal tuberculosis by MRI. J Bone Joint Surg Br. 1994;76:863-869.

26. Dhammi IK, Jain AK, Buxi TB. Non-operative management of an intramedullary tuberculoma. Trop Doct. 2002;32:44-45.

27. Jena A, Banerji AK, Tripathi RP, Gulati PK, Jain RK, Khushu S, Sapra ML. Demonstration of intramedullary tuberculomas by magnetic resonance imaging: a report of twocases. $\mathrm{Br} \mathrm{J}$ Radiol. 1991;64:555-7.

28. Smids C, Kouijzer IJ, Vos FJ, Sprong T, Hosman AJ, de Rooy JW, Aarntzen EH, de Geus-Oei LF, Oyen WJ, Bleeker-Rovers CP. A comparison of the diagnostic value of MRI and 18F-FDG-PET/CT in suspected spondylodiscitis. nfection.2017; 45:41-49. DOI: 10.1007/s 15010-016-0914-y. 